\title{
EDITORIAL
}

\section{Scope of Scientific Research in Bangladesh}

\author{
M Abdullah Yusuf ${ }^{1}$ \\ ${ }^{1}$ Assistant Professor, Department of Microbiology, National Instittue of Neurosceinces \& Hospital, Sher-E-Bangla Nagar, Agargaon, \\ Dhaka-1207, Bangladesh; Email: ayusuf75@yahoo.com; Cell no.: +8801817565830
}

[How to cite this article: MA Yusuf. Scope of Scientific Research in Bangladesh. J Sci Found 2014;12(1):1]

Bangladesh is a densely populated country with 160 million of population. There are so many resources that proper utilization can give a great boost up to the economics of this country. There are so many well reputed universities and Institutions. Majorities are related to science which may be medical or non-medical. Many of these have well-established laboratory facilities. In these laboratories research works can be performed if any laboratory based research work is needed.

In medical sector, it is very easy to collect the data on which a research work can be done. It has been said that developed countries have less amount of people having lack of data, but they have many scientific articles. On the other hand in Bangladesh there is huge number of patients with lack of research works. In this context the scientist should come forwards to do research works.

During a research work the scientist can concentrate on the objectives of the work. Anyone can do the research work if the scientist has that type of moto. This can be done if there is a mentality to do the work. There are huge scopes of financial agency to help to perform the work. Many scientists in all around the world want to do the research work with the collaboration of the scientist of this country. Therefore, there is a scope of multicentre study in this country. This type of study is conducted in many Institutions as well as Universities. Many United Nationals agencies are giving a lot of fund for conducting the research work. One of these agency is the World Health Organization. This UN agency has many research wings from which the funds are giving to the researchers. The human diseases have grossly divided into non-communicable and communicable diseases according to the contagious nature. The management of the communicable diseases by vaccination gives a tremendous prevention of these categories of disease. On the contrary, the non-communicable diseases (NCDs) become emerge as a huge burden to the country. In a current prediction the diabetes mellitus will occurs in one person in every ten person in this country in the year of 2020. These will create a huge burden of patients. These will gives a huge opportunities to do the research work. This scope of research works can help the scientist to publish the research papers which will gives a lots of scopes on different innovations.

There are so many limitations during a research works. The researchers should delimit these problems. Delimitations refer to those characteristics that limit the scope and define the conceptual boundaries of your research. This is determined by the conscious exclusionary and inclusionary decisions you make about how to investigate the research problem. In other words, not only tell the reader what it is studying and why, but it must also acknowledge why it is rejected alternative approaches that could have been used to examine the topic. Obviously, the first limiting step was the choice of research problem itself. However, implicit are other, related problems that could have been chosen but were rejected. These should be noted in the conclusion of your introduction. The point is not to document every possible delimiting factor, but to highlight why obvious issues related to the research problem were not addressed. Therefore, all the scientists of Bangladesh should come forwards to do research works and take this scope and opportunities, so that this can give a great boost up to the field of research. [J Sci Found 2014;12(1):1] 